\title{
Correction to: Discriminant functions for sex estimation using the rib necks in a Spanish population
}

\section{Manuel Partido Navadijo ${ }^{1} \cdot$ Ignacio Fombuena Zapata $^{1} \cdot$ Erik Adrián Borja Miranda $^{1} \cdot$ Inmaculada Alemán Aguilera $^{1}$}

Published online: 19 March 2021

(c) Springer-Verlag GmbH Germany, part of Springer Nature 2021

Correction to: International Journal of Legal Medicine (2021) https://doi.org/10.1007/s00414-021-02537-8

The original article contains an error in Fig. 1. In the published article, two of the measurements were incorrect. "LT" should be replaced with "LH" and "LSHN" should be "LSNT" and vice versa. The correct figure is presented here.

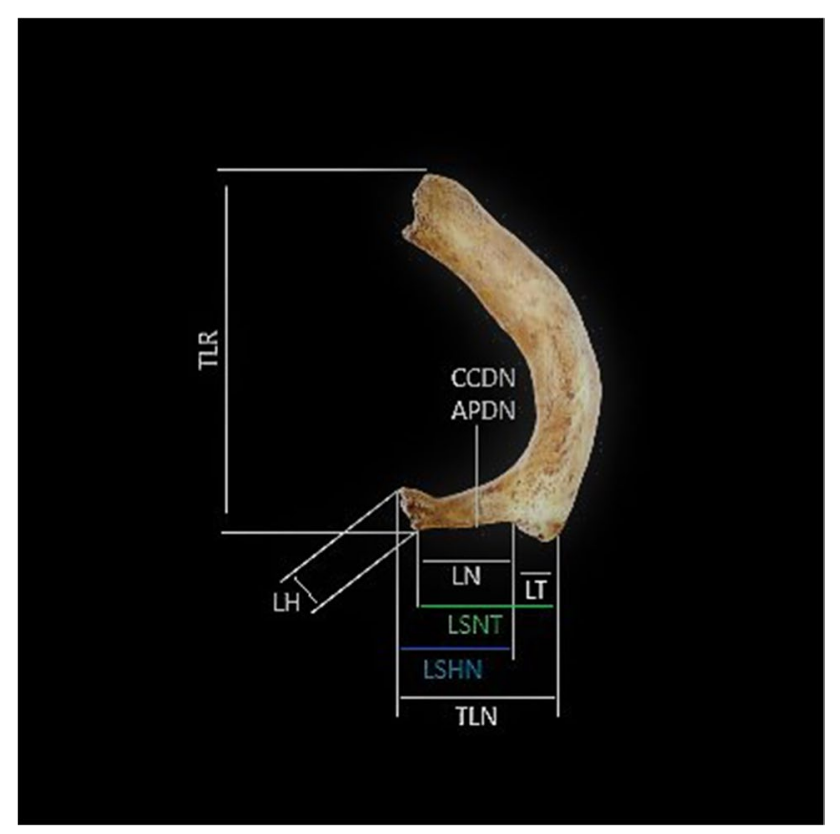

The original article has been corrected.

Publisher's note Springer Nature remains neutral with regard to jurisdictional claims in published maps and institutional affiliations.

The original article can be found online at https://doi.org/10.1007/ s00414-021-02537-8.

\footnotetext{
Manuel Partido Navadijo mpartido@ugr.es

1 Laboratory of Anthropology, Department of Legal Medicine, Toxicology and Physical Anthropology, University of Granada, Parque Tecnológico de la Salud, Avda. de la Investigación, 11, 18016 Granada, Spain
} 